\title{
Australia antigen and antibody in British patients with leprosy
}

\author{
TIN SHWE AND A. J. ZUCKERMAN
}

From the Department of Clinical Tropical Medicine and Burma Leprosy Service and the Department of Bacteriology and Immunology, London School of Hygiene and Tropical Medicine

SYNOPSIS Seventy-five sera collected from leprosy patients in England were tested for Australia antigen and antibody. Australia antigen was detected in only two patients with lepromatous leprosy and in one patient with borderline pure leprosy. Antibody to Australia antigen was found in one patient with lepromatous leprosy. These findings differ from previous reports and it is suggested that the frequency of Australia antigen in lepromatous leprosy is a function of the incidence of this antigen in the general population rather than increased genetic susceptibility to chronic infection.

Australia antigen has been shown to be closely associated with viral hepatitis type B (Zuckerman, 1969) and with chronic carriage of the serum hepatitis virus. It is also common in patients with chronic diseases characterized by a prolonged and usually severe impairment of the immune mechanism, particularly of cellular immunity. Included among these are some forms of lymphocytic leukaemia, patients with Down's syndrome, patients with chronic renal failure, and patients with lepromatous leprosy. The antigen is rarely detected in the normal North American and west European populations (WHO Memorandum, 1970).

Antibody to Australia antigen is found with varying frequency in patients who have received multiple transfusions of blood and blood products. The antibody is rarely found by currently available techniques in healthy persons though it appears to be considerably more common in tropical populations (WHO Memorandum, 1970).

In leprosy, Blumberg, Melartin, Lechat, and Guinto (1967) and Blumberg, Melartin, Guinto, and Lechat (1970) reported a high incidence of Australia antigen in patients with lepromatous leprosy, and postulated that the presence of Australia antigen is associated with that of detectable acid-fast bacilli. It was also postulated that a gene $\mathrm{Au}^{1}$, which confers increased susceptibility to chronic infection with hepatitis virus, may also confer susceptibility to chronic infection with other microorganisms. The question was asked if a high incidence of Australia antigen is also present among leprosy patients in England, where the socioReceived for publication 19 October 1971. economic environment is totally different from that of the tropics.

\section{Materials and Methods}

Seventy-five sera were collected from leprosy patients. The diagnosis in 60 patients was lepromatous or near lepromatous leprosy; five patients with borderline leprosy and 10 patients with tuberculoid or near tuberculoid leprosy had attended the outpatient clinic of the Hospital for Tropical Diseases, London.

Each sample of serum was tested by the twodimensional micro-Ouchterlony immunodiffusion technique as described by Zuckerman and Taylor (1969). The presence of antigen or antibody was shown by the development of a visible precipitin arc between the centre well and the peripheral wells containing the sera under test. The results were read daily for five days.

\section{Results}

Australia antigen was detected in two patients with lepromatous leprosy, and in one patient with borderline pure leprosy. Antibody to Australia antigen was detected in one patient with lepromatous leprosy. The remaining samples were free of detectable antigen and antibody.

\section{Discussion}

In this study Australia antigen was detected in only twe of 60 sera obtained from British patients with 
lepromatous leprosy. Antibody to Australia antigen was detected in another patient. This antigen was found in one of five patients with borderline pure leprosy. Neither antigen nor antibody was detected in the 10 patients with tuberculoid leprosy. The difference in the prevalence of Australia antigen and antibody among these grours is not significant.

These findings differ from the previous reports. Thus, Blumberg et al $(1967,1970)$ found Australia antigen in $9.6 \%$ cf lepromatous leprosy patients, $3.9 \%$ of tuberculoid leprosy, and $5.1 \%$ of controls in Cebu, in the central Phillipines. Nevertheless, the frequency of detectable antigen in the British patients with leprosy is much higher than in the healthy blood donor population in the United Kingdom, which varies from 1 in 500 to 1 in 1200 blood donors. This observation, however, can be readily explained on the basis of depressed immune response and it is widely recognized that Australia antigen is found more frequently in immunosuppression. Lepromatous leprosy is undoubtedly associated with severe impairment of the immune mechanism as shown by failure to respond to intradermal injection of lepromin, delayed allograft rejection, and nontransformation of lymphocytes after stimulation with phytohaemagglutinin.

We would, therefore, favour the depression of cellular immunity in lepromatous leprosy as the raason for the association with Australia antigen rather than increased genetic susceptibility to chronic infection. This explanation is in agreement with the failure to detect Australia antigen in 218 patients with leprosy in Brazil and with the conclusion thato Australia antigen is not found with increased fre-흘 quency in lepromatous leprosy in areas where the $\frac{\bar{\sigma}}{\bar{\sigma}}$ antigen is uncommon in the general population $\mathbb{\Phi}^{\Phi}$ (Salzano and Blumberg, 1970).

T.S. is grateful to Professor A. W. Woodruff and $\overrightarrow{0}$ Dr D. S. Ridley of the Hospital for Tropical $\overrightarrow{\vec{\omega}}$ Diseases, London, and Professor J. L. Turk of the Royal College of Surgeons, London, for all theirō guidance and help. We also wish to thank Dr Susano Sullman for technical assistance.

\section{References}

Blumberg. B. S., Melartin, L., Guinto, R. S., ard Lechat, M. (1970) Lepromatous leprosy ard Australia antigen with comments on the genetics of leprosy. J. chron. Dis., 23, 507-516.

Blumberg, B. S.. Melartin. L.. Lechat, M.. and Guinto, R. (1967) Z Association between lepromatous leprosy and Australia anti gen. Lancet, 2, 173-176.

Salzano. F. M., and Blumberg. B. S. (1970). The Australia antigen in' Brazilian healthy persons and in leprosy and leukaemia patients. J. clin. Path., 23, 39-42.

World Health Organization (1970). Memorandum. Viral hepatitis and tests for the Australia (hepatitis-associated) antigen and antio body. Bull. Wld Hlth Org., 42, 957-992.

Zuckerman, A. J. (1969). Viral hepatitis and the Australia-SH artigen Viature (Lond.), 223, 569-572.

Zuckerman. A. J., and Taylor, P. E. (1969). Persistence of the serum hepatitis (SH-Australia) antigen for many years. Nature (Lond.). 223. $81-82$. 